\title{
UNDERSTANDING THE CHALLENGES OF MULTICULTURAL TEAM MANAGEMENT ${ }^{1}$
}

\author{
DOI: 10.17261/Pressacademia.2018.954
}

JBEF- V.7-ISS.3-2018(5)-p.259-268

\section{Nusret Sogancilar ${ }^{1}$, Husniye Ors ${ }^{2}$}

${ }^{1}$ Gazi University, Faculty of Economics and Administrative Sciences, Ankara, Turkey. nsrtsgnclr@gmail.com, ORCID: 0000-0002-9729-5372

${ }^{2}$ Gazi University, Faculty of Economics and Administrative Sciences, Ankara, Turkey. ohusnive@gmail.com, ORCID: 0000-0002-8319-3340

Date Received: July 1, 2018

Date Accepted: September 5, 2018

\section{To cite this document}

Sogancilar, N., Ors, H. (2018). Understanding the challenges of multicultural team management. Journal of Business, Economics and Finance (JBEF), V.7(3), p.259-268.

Permemant link to this document: http://doi.org/10.17261/Pressacademia.2018.954

Copyright: Published by PressAcademia and limited licenced re-use rights only.

\section{ABSTRACT}

Purpose- This study aims to explore the challenges confronted by executive managers while managing multicultural teams, and the solutions they deliver to cope with these matters. What is aimed to accomplish is to comprehend these challenges from the standpoint of managers. While trying to understand the problems and exhortations related to multicultural team management, culture and core cultural dimensions were utilized in the study.

Methodology- Criterion sampling method, which is a kind of purposive sampling method, was employed in the study. The data for the study was collected through 14 in-depth interviews directed to executive managers of MNCs operating in Turkey. The questions that generate our data consist of open-ended questions. The statements of managers were analyzed by content analysis and sorted into corresponding categories. These categories and solutions based upon manager's experiences were presented accordingly.

Findings- Implications indicate that most frequently confronted challenges are ineffective communication and misunderstandings, different working styles and expectations of group members, and intolerance and lack of knowledge related to diversity. On the other hand, in order to cope with these challenges, managers state that it is significant to embrace diversity and encourage group members to acknowledge it as well as become approachable and eager to learn more. Last but not least communicating in the simplest form has been accentuated. Conclusion- To sum up briefly, successful managers are expected to possess the competency to adapt different management styles and they are also expected to be flexible enough to switch from one to another.
\end{abstract}

Keywords: Multicultural teams, core cultural dimensions, cross-cultural management, international business, multinational companies. JEL Classification: F23, M12, M16

\section{INTRODUCTION}

Having multicultural teams in today's globalized business world is quite widespread for companies. The reason behind this phenomenon is considered to be the increasing mobility of people and labor on a global scale. Within this context, multicultural work groups have become prevalent and rapidly changing work environment has set novel challenges both for managers and for employees. Therefore, the role of managers as to effectively leading multicultural teams as well as understanding and handling the challenges arising for this reason is pretty significant (Matveev and Milter 2004).

\footnotetext{
1 This paper is a revised and expanded version of a paper presented at the Global Business Research Congress in 2018.
}

Simply put, it is considered that multinational companies (MNCs) prefer directly investing in foreign markets for certain reasons including market-seeking (desire to find new buyers), resource-seeking (desire to access to cheaper inputs), 
strategic asset-seeking (desire to build distribution networks and acquire cutting-edge technologies) and efficiency-seeking (Dunning, 2002). Along with that, mergers and acquisitions performed between foreign and domestic companies are considered to influence the number of foreign employees working for the company and consequently the number of multicultural teams in international organizations. Studies conducted to investigate MNCs exhibit that one of the serious issues faced by these companies is the management of cross-cultural differences. This is because culture profoundly influences the attitudes of managers, relations in the company, technology transfer, and many other activities (Helvacioğlu and Özutku, 2010). Within this context, it may be regarded that major problems arise in work environments where people from diverse cultural backgrounds are working together. Previous studies conducted in this realm, mainly focuses on either proper leadership styles that are required to adopt to manage culturally diverse teams or the issues confronted by team members and how they handle these problems including language differences, misunderstandings and miscommunication (Mäkilouko, 2004; Behfar et al., 2006; Ramthun and Matkin, 2012; Aritz and Walker, 2014; Lisak and Erez, 2015). Also, there are studies conducted to comprehend the challenges of virtual teamwork (Heimer and Vince, 1998; Jarvenpaa and Leidner, 1999; Oertig and Buergi, 2006).

In this study, instead of concentrating on the differences of individual team members and their cultural backgrounds, it has been aimed to address the challenges faced by executive managers while managing multicultural teams as well as the solutions delivered by them. In other words, our goal is to develop an understanding of the challenges faced by managers and the way they handle these challenges. This study is going to concentrate on managers who work for MNCs operating in Turkey since they are more likely to work with people from diverse cultures and confront challenges stemming from these differences that are common in multicultural teams. Comprehending these challenges from the standpoint of managers is what we aim to accomplish. The outline of this study is charted as follows. Following section presents the literature review focusing on the definition of culture, the dimensions of culture, multicultural teams and the advantages and disadvantages of having multicultural teams in the organization. Section 3 will present the methodology, including sample selection, data collection and data analysis method. In Section 4, the findings of the study will be given and discussed through core cultural dimensions lens. It will cover descriptive findings, the challenges faced by managers in managing multicultural teams and the solutions proposed by them. Finally, Section 5 will provide concluding remarks. Limitations of the study and avenues for future research will also be outlined in the last section.

\section{LITERATURE REVIEW}

\subsection{Defining Culture}

Since the concept of culture has been approached by myriad of researchers as well as disciplines including sociology, psychology, anthropology, history and so on, it is difficult to come up with an exact definition of culture. Therefore, it can be said that because looking for a definition that does not overlook the richness of culture and that encompasses all the definitions proposed related to culture is tricky and complicated, one may encounter various definitions and approaches related to the concept of culture. Even though not-having-a-specific-definition-of-culture view is the position on which there is a consensus, by Browaeys and Price (2008: 3), it is put forward that there is a concrete feature of culture which is that "it is something all human learn in one way or another." Despite the complexity and richness of the notion of culture, Hofstede (1980: 25) defines culture as "the collective programming of the mind which distinguish the members of one human group from another." The definition proposed by Hofstede is frequently used in the cross-cultural studies.

In their study, Schneider and Barsoux (2003) give a visual picture of an ocean that contributes to the interpretation of culture's levels. At the top, behaviors (architecture, language, cuisine and so on) take place, which correspond to the surface of the ocean and are visible and observable. Beliefs, norms and values (rules, what is right or wrong and so on) fall in the middle, which can be determined through surveys and interviews. And undermost, assumptions which are not easy to explore and where inferences can be made through interpretations, take part.

In addition, Chao and Moon (2005) define culture as a "Cultural Mosaic" that encompasses the dimensions including demography (age, gender, race), geography (climate, urban-rural) and association (family, religion). Following these definitions, it can be said that culture is open to change and serves as a glue which is made of both observable and unobservable commonly shared ingredients, which holds people together and enables them to interpret the world surrounding them as well as differentiates them from others with its distinctive characteristics.

\subsection{Core Cultural Dimensions (CCDs)}

In the literature, there are multiple models that attempt to explain national cultures and that also have been frequently used and cited in cross-cultural studies. This divergence or lack of convergence deriving from the multiplicity refers to "culture theory jungle". In their study, Nardon and Steers (2009) integrate the six most commonly utilized models that are proposed by Kluckhohn and Strodtbeck, Hofstede, Hall, Trompeenars, Schwartz and GLOBE study. Then, they suggest, 
based on their assessment, five common themes referring to core culture dimensions (CCDs) that include HierarchyEquality, Individualism-Collectivism, Mastery-Harmony, Monochronism-Polychorism, Universalism-Particularism (see Table 1 for the summary). Therefore, in order to hold a comprehensive understanding and make more meaningful comparisons, CCDs are employed in the study. In addition, it is highly recommended that readers get to the original paper for more detailed information and comprehension related to CCDs.

Table 1: Core Cultural Dimensions (CCDs)

\begin{tabular}{|l|l|}
\hline CCDs & Focus of Dimensions \\
\hline Hierarchy-Equality & $\begin{array}{l}\text { Power distribution in organizations and society: Extent to which power and authority } \\
\text { in a society are distributed hierarchically or in a more egalitarian and participative } \\
\text { fashion. }\end{array}$ \\
\hline Individualism-Collectivism & $\begin{array}{l}\text { Role of individuals and groups in social relationships: Extent to which social } \\
\text { relationships emphasize individual rights and responsibilities or group goals and } \\
\text { collective action; centrality of individuals or groups in society. }\end{array}$ \\
\hline Mastery-Harmony & $\begin{array}{l}\text { Relationship with the natural and social environment: Beliefs concerning how the } \\
\text { world works; extent to which people seek to change and control or live in harmony } \\
\text { with their natural and social surroundings. }\end{array}$ \\
\hline Monochronism-Polychronism & $\begin{array}{l}\text { Organization and utilization of time: Extent to which people organize their time } \\
\text { based on sequential attention to single tasks or simultaneous attention to multiple } \\
\text { tasks; time as fixed vs. time as flexible. }\end{array}$ \\
\hline Universalism-Particularism & $\begin{array}{l}\text { Relative importance of rules vs. relationships in behavioral control: Extent to which } \\
\text { rules, laws, and formal procedures are uniformly applied across societal members or } \\
\text { tempered by personal relationships, in-group values, or unique circumstances. }\end{array}$ \\
\hline
\end{tabular}

Source: Nardon and Steers (2009: 10).

Moreover, based on the countries' central tendencies in cultural characteristics, Nardon and Steers (2009) determine country clusters in their study. These include nine clusters which are Anglo, Arab, East European, East/Southeast Asian, Germanic, Latin American, Latin European, Nordic, and Sub-Saharan Africa (Nardon and Steers, 2009: 17-19). In our study, CCDs and these country clusters will be utilized to make comparisons, interpretations and interference.

\subsection{What is a Multicultural Team?}

Human beings have been experiencing collaboration and cooperation to safeguard the continuity of their existence ever since they existed. Cooperation and collaboration, in this sense, may be regarded as worthwhile and helpful not only for survival but also for efficiency and satisfaction. Hence, emergence and creation of teams can be attributed to this notion (Halverson and Tirmizi, 2008).

Globalization and recent developments in technology have profoundly influenced societies, businesses and the work environment. This is because increasing mobility of labor and entrepreneurs along with capital movements, spread of information \& technology and foreign trade activities peaked in recent years. Changes in the work environment stemming from globalization have brought about some practical concerns regarding the management of multicultural teams (Thomas, 1999). According to Jarvenpaa and Leidner (1999), multicultural teams can be formed in three ways. Firstly, a team may consist of members from diverse cultural backgrounds including expats or ethnic minorities working together in the same country. Secondly, it may possess members who are dispersed across many countries but occasionally meet up in person. And thirdly, virtual teams that possess members from various countries, working together via electronic devices and medias and not meeting in person. It is important to mention right here that we are going to focus on the first type of teams in this study.

Multicultural teams are defined as "task-oriented groups comprising people of different cultural backgrounds" by Marquardt and Horvath (2001). In addition, in their study, Halverson and Tirmizi (2008: 5) define multicultural teams as

"a collection of individuals with different cultural backgrounds, who are interdependent in their tasks, who share responsibility for outcomes, who see themselves and are seen by others as an intact social entity embedded in one or more larger social systems, and who manage their relationships across organizational boundaries and beyond".

\subsection{Pros and Cons of Having Multicultural Teams}

In the literature, there are several studies accentuating the advantages and disadvantages of having multicultural teams. Brannen and Salk (2000) suggest that cultural diversity doesn't impact team performance in a negative way. In other words, it is claimed that what creates a conflict in a team is not the differences of team members. A review completed by William and O'Reilly (1998) conclude that diversity has no predictable effect on team performance. In addition, cultural diversity in 
an organization is asserted to serve as an asset instead of liability (Williams and O'Reilly, 1998; Stahl et al., 2010). Some studies show that heterogenous teams outperform homogenous teams. It is suggested that multiple perspectives, varied experiences, different problem-solving and decision-making styles and smart ideas prevail in multicultural teams (Adler, 2002).

Due to diversity, multicultural teams are more prone to face difficulties including language barriers, ineffective communication and differences in communication styles (Adler, 2002). When heterogeneity in groups increases, it is considered that cultural differences bring about miscommunication in the group and undermine the development of group norms (Bettenhausen and Murnighan, 1985; Jehn et al., 1999; Ely \& Thomas, 2001; Behfar et al., 2006). Diversity is likely to create a propensity toward conflict and subconsciously-held cultural differences and sources of conflict are tough to detect and annihilate (Kirchmeyer and Cohen, 1992). According to De Dreu \& Weingart (2003), conflicts in multicultural teams are negatively related to team performance.

As it can be understood, there are certain advantages and disadvantages of having multicultural teams or diversity in the organization. The attitude of an organization towards diversity may be considered to be influenced by the way a manager handles them and perceives the pros and cons of these differences. While some managers underestimate cultural diversity, and try to remove it in the organization, some might deem these differences as an advantage enhancing company performance and try to support and encourage this diversity in the organization. Therefore, view of the organization on this matter is likely to be impressed by the managers working for the organization.

\section{DATA AND METHODOLOGY}

For this study, data was collected from primary and secondary sources. Secondary sources consisted of books, articles and magazines which were used to constitute the theoretical parts of the study. Main data for the study was collected through in-depth interviews directed to executive managers of MNCs operating in Turkey. The objective of the interviews was to explore the problems of managing multicultural teams and identify the solutions, within this context, recommended by executive managers. The data was obtained from answers given to open-ended questions. The statements of managers were analyzed by content analysis.

As mentioned, study focused on the executive managers working for MNCs operating in Turkey. However, it was not easy to access to a list indicating the name of MNCs in Turkey. Therefore, it was made use of the list published by Fortune Magazine that revealed the biggest 500 companies of 2017 in Turkey. Purposive sampling method, which is one of the most commonly used and the fittest sampling techniques in qualitative researches (Marshall, 1996; Palys, 2008: 697; Sekaran and Bougie, 2016: 248), was employed in the study. Based upon the objective of the studies, purposive sampling method is classified into certain kinds. Taken this into consideration, appropriate sampling method for this study was considered to be criterion sampling (Palys, 2008: 697). In this sense, companies in the sample of the study were selected from the list based upon their country-origins. It was aimed to get an appointment from the first 50 foreign corporations in the list and ultimately 14 in-depth interviews were conducted by appointment.

First part of the questionnaire concerns about the personal background of the participators. Demographic or general information that executive managers were requested to answer was determined as gender, age, nationality, educational background and work experience (years). Lastly, main questions of the study consisted of "As compared to homogeneous teams, what are the challenges confronted while managing multicultural teams?" and "How do you address or manage these challenges?".

\section{FINDINGS AND DISCUSSIONS}

\subsection{Sample Profile}

The sample of the study consisted of 14 individuals with multicultural team management experience. While 64 percent of the participants were male, the rest, namely 36 percent, were female participants. Ages of the participants ranged from 26 to 39 , with an average of about 32 years. Almost three out of four (72 percent) of the participants were from two countries, Turkey and Germany. In addition, 43 percent (six out of 14) of participants in the sample had a master's degree while 57 percent (eight out of 14) participants had a bachelor's degree. On the basis of work experience, while the maximum year was 12, the minimum year was 3 with an average of about 7 years (see Table 2 and Table 3). 
Table 2: Demographic Characteristics of Respondents

\begin{tabular}{|l|l|l|l|}
\hline Demographic Variables & Frequency & Percentage \\
\hline \multirow{3}{*}{ Gender } & Female & 5 & 36 \\
\cline { 2 - 4 } & Male & 9 & 64 \\
\cline { 2 - 4 } & & $\mathbf{1 4}$ & $\mathbf{1 0 0}$ \\
\hline \multirow{3}{*}{ Age } & $26-32$ & 8 & 57 \\
\cline { 2 - 4 } & $33-39$ & 6 & 43 \\
\cline { 2 - 4 } & & $\mathbf{1 4}$ & $\mathbf{1 0 0}$ \\
\hline \multirow{3}{*}{ Education Level } & Undergraduate & 8 & 57 \\
\cline { 2 - 4 } & Graduate & 6 & 43 \\
\cline { 2 - 4 } & & $\mathbf{1 4}$ & $\mathbf{1 0 0}$ \\
\hline \multirow{3}{*}{$\begin{array}{l}\text { Work Experience } \\
\text { (year) }\end{array}$} & $3-7$ & 10 & 71 \\
\cline { 2 - 4 } & $8-12$ & 4 & 29 \\
\cline { 2 - 4 } & & $\mathbf{1 4}$ & $\mathbf{1 0 0}$ \\
\hline
\end{tabular}

Besides, as can be seen in Table 3, participants were mainly from countries that value hierarchy (64 percent), collectivism (64 percent), harmony (57 percent), monocronism (57 percent) and particularism (64 percent), respectively.

Table 3: Distribution of Respondents Based on Nationality and CCDs

\begin{tabular}{|c|c|c|c|c|c|c|c|c|c|c|c|}
\hline \multirow{2}{*}{ Country } & \multirow[b]{2}{*}{ Percentage } & \multicolumn{2}{|c|}{$\begin{array}{l}\text { Hierarchy/ } \\
\text { Equality }\end{array}$} & \multicolumn{2}{|c|}{$\begin{array}{l}\text { Individualism/ } \\
\text { Collectivism }\end{array}$} & \multicolumn{2}{|c|}{$\begin{array}{l}\text { Mastery/ } \\
\text { Harmony }\end{array}$} & \multicolumn{2}{|c|}{$\begin{array}{l}\text { Monochronism/ } \\
\text { Polychronism }\end{array}$} & \multicolumn{2}{|c|}{$\begin{array}{l}\text { Universalism/ } \\
\text { Particularism }\end{array}$} \\
\hline & & H & E & I & C & $M$ & H & $M$ & $\mathbf{P}$ & $U$ & $\mathbf{P}$ \\
\hline Turkey & 43 & 6 & & & 6 & & 6 & & 6 & & 6 \\
\hline Germany & 29 & & 4 & 4 & & 4 & & 4 & & 4 & \\
\hline Poland & 7 & 1 & & & 1 & 1 & & 1 & & & 1 \\
\hline S. Korea & 7 & 1 & & & 1 & & 1 & 1 & & & 1 \\
\hline China & 7 & 1 & & & 1 & & 1 & 1 & & & 1 \\
\hline The USA & 7 & & 1 & 1 & & 1 & & 1 & & 1 & \\
\hline Total & 7 & 9 & 5 & 5 & 9 & 6 & 8 & 8 & 6 & 5 & 9 \\
\hline \multirow{2}{*}{ Percentage } & 100 & 64 & 36 & 36 & 64 & 43 & 57 & 57 & 43 & 36 & 64 \\
\hline & & \multicolumn{2}{|c|}{100} & \multicolumn{2}{|c|}{\begin{tabular}{|l|}
100 \\
\end{tabular}} & \multicolumn{2}{|c|}{100} & \multicolumn{2}{|c|}{100} & \multicolumn{2}{|c|}{100} \\
\hline
\end{tabular}

\subsection{Research Findings}

As a result of content analysis obtained from primary data, the challenges that managers confront, and the solutions they have come up with are identified as follows. The challenges grouped under three headings including ineffective communication and misunderstandings, different working styles and expectations, and intolerance and lack of knowledge related to diversity. On the other hand, the solutions that managers come up with are also categorized under three headings. They include embracing diversity and encouraging team members to acknowledge it, becoming approachable and eager to learn more, and communicating in a simple and straightforward way. In the following sections, both the problems and advices related to multicultural team management will be detailed and discussed. Furthermore, taking into account the cultural characteristics of the participants presented in Table 1 and Table 3, Table 4 and Table 5 respectively indicate the challenges that managers confront and the solutions they come up with as well as the managers' cultural dimensions.

\subsubsection{The Challenges}

Ineffective Communication and Misunderstandings: 71 percent (ten out of 14) of the participants state that the most significant challenge they face in multicultural team management is ineffective communication and misunderstandings. Since they come from diverse cultural settings, it is very likely for team members to have different communication styles. Different communication styles of group members are likely to create controversy about certain issues including the deadlines of the assignments and due dates of the projects. So, one of the problems that managers face within this context is the controversy among group members about the deadline of a task or a project. For instance, when it is said that the task must be submitted at the end of the day; some people are likely to regard it as the end of the shift whereas the interpretation of 'at the end of the day' is likely for others to be the beginning of a new day or midnight. Therefore, it can be said that communication is harder, and misunderstandings occur very easily. Besides, the way you talk and say is important because some group members expect to be addressed directly whereas others expect it to happen indirectly. In other words, some nations value directness whereas others see this being rude. Also, it occupies more time to explain the 
assignments and tasks in heterogeneous teams. In homogenous teams, members are more willing to share their ideas and debates are less superficial. For instance, if more than two members of the team come from different countries, the language they use is always English unless they have another common language they better express themselves. Therefore, communication is harder and requires efforts to avoid misunderstandings due to language barriers. In this context, not sharing the same language is likely to create misunderstandings and disagreements among team members. Some reasons including inadequate language skills are the obstacles to clearly and assertively express what they want or think even though team members exactly know what is required to do. Therefore, inadequate language skills of some team members prevent them from expressing themselves clearly and assertively. This kind of challenge is likely to occur especially during brainstorming sessions or meetings. And because of misunderstandings, multicultural teams face a lot more problems than teams that are homogenous. These problems cause such issues including mistrust, lack of motivation, misunderstanding of the tasks and schedules, and absenteeism.

Less than half of the participants addressing ineffective communication and misunderstandings as a problem come from cultures that value equality. Failures of team members in assertively expressing themselves and avoidance from participating in decision-making processes are some of the problems that managers confront. The reason that managers consider it as a problem might be that they stress low power distance in the saddle. In other words, it can be attributed to managers' willingness to manage their teams in a participative style which implies the distribution of authority and responsibility among team members. In addition, most of the managers value a collectivist structure due to their cultures. They tend to communicate in a subtle and indirect way. This is more likely to create problems for team members who are from individualistic cultures in which both sending and receiving the message in a straightforward way are prevalent. On the other hand, universalist cultures can be simply defined as rule-based cultures and managers from these cultures are more prone to adopt management styles based on rules, strict deadlines and schedules in order to be able to control unexpected events and minimize uncertainty (Nardon and Steers, 2009). Misunderstandings among team members related to deadlines, schedules and due dates might be interpreted as both managers' tolerance for rule-breakings and team members' tendency to do things formally due to their cultural backgrounds (see Table 4).

Different working styles and expectations: Approximately 36 percent (five out of 14) of the participants accentuate that the second most important problem in the multicultural teams is different working styles and expectations of team members stemming from diverse cultural backgrounds. The way team members require directions to achieve tasks varies based on cultures. For instance, while some of the members expect to have autonomy on their task, others are likely to expect explicit directions from the team manager in order to set to work. Attitudes, values and the way of building relationship differ from culture to culture. Working styles and ethics among multicultural team members are very likely to differ as well. While some cultures more emphasize on private time and work-life balance, in some cultures it might be more acceptable and will not be perceived as exploitation to ask employees to work more than eight hours a day. In addition, perception of responsibility and authority will be different. Moreover, the way people are motivated is likely to be different based upon their culture. Some people are likely to get motivated with a suitable compensation system in a stable environment. On the other hand, for some people, a reasonable salary and a working environment in which relationship matters would be more motivational. Nevertheless, Chinese, Korean and Indian people will be much happier to follow instructions from their superiors compared to those who are accustomed to working independently and do not request instructions or guidance.

All the managers, who regard work-life balance as a problem in the team, have the characteristics of polychronic cultures in which there is no significant lines between personal life and work. Therefore, for the team members who pay regard to work-life balance and appreciate the separation of these two, attitudes of the managers, in this respect, are likely to create difficulties and unlikely to avert frictions. In 'harmony' and collectivist cultures, quality of life, relationship-based work environment and loyalty to a group are comparatively prevalent characteristics. For the managers and team members who internalize these characteristics, people from individualist and 'mastery' cultures, in which personal goals, achievement, loyalty to oneself are highly acknowledged, will be the reason of disturbance and rage (see Table 4).

Intolerance and lack of knowledge related to diversity: About 28 percent (four out of 14) of the participants reckon that intolerance and lack of knowledge related to diversity is a problem that must be addressed. In the words of a manager, when you approach someone in your team, the very first thing you should keep in mind is that you must respect for diversity. In your team, there might be people who come from different countries, speak different languages, believe in different Gods or have different skin tones. Do not use these differences to banter or start a conversation. Also, the way people do their jobs and behave under different circumstances will not be the same. Team members, if they are not trained about diversity along with cultural tendencies, will be more irritated and less tolerant about the differences. Intolerance and lack of awareness of team members and managers about these issues lead to frictions and conflicts in the team. Then, team members will underperform under these circumstances unless the manager knows how to tackle these issues. 
As seen in Table 4, managers considering intolerance and lacking in diversity understanding as a problem come from cultures in which harmony and collectivism are valued. In these cultures, welfare of the in-group members and coherence are strictly accentuated. Also, suppressing, ostracizing and assimilating the differences are considered to be quite widespread in these cultures. A Japanese proverb 'The nail that sticks out gets banged down' emphasizes that the individualistic tendencies of people is not a good thing and will not be welcomed in a collectivist society (Markus and Kitayama, 1991).

Table 4: Challenges That Managers Confront and the Managers' CCDs

\begin{tabular}{|l|l|l|l|l|l|}
\hline & $\begin{array}{l}\text { Hierarchy/ } \\
\text { Equality }\end{array}$ & $\begin{array}{l}\text { Individualism/ } \\
\text { Collectivism }\end{array}$ & $\begin{array}{l}\text { Mastery/H } \\
\text { armony }\end{array}$ & $\begin{array}{l}\text { Monochronism/ } \\
\text { Polychronism }\end{array}$ & $\begin{array}{l}\text { Universalism/ } \\
\text { Particularism }\end{array}$ \\
\hline $\begin{array}{l}\text { Ineffective Communication and } \\
\text { Misunderstandings }\end{array}$ & Both & Both & Both & Both & Both \\
\hline $\begin{array}{l}\text { Different working styles and } \\
\text { expectations }\end{array}$ & Hierarchy & Collectivism & Harmony & Polychronism & Particularism \\
\hline $\begin{array}{l}\text { Intolerance and lack of } \\
\text { knowledge related to diversity }\end{array}$ & Hierarchy & Collectivism & Harmony & Polychronism & Particularism \\
\hline
\end{tabular}

\subsubsection{Solution Offers}

Embrace diversity and encourage group members to acknowledge it: About 86 percent (12 out of 14) of the participants suggest embracing diversity and encouraging group members to acknowledge it. A work environment in which managers embrace diversity while encouraging group members to acknowledge it is quite significant. Group members need to be trained about cultural diversity and working in a multicultural team. They should know that they must embrace this diversity and respect the differences. So, the manager should be aware of and alert to conflicts among team members and provide knowledge and encourage members to learn about cultural differences. Openness to new things and unfamiliar cultures as well as high level of tolerance is important. Therefore, it is stated the importance of always reminding oneself that attitudes coming from another culture might mean different than in your own culture and ethnocentrism will not serve the purpose in this context. Also, learning the way of building relationships regardless of the differences is important if one wants to succeed in a multicultural team. Change in a team starts with the manager. Listening to and respecting the opinions of other members, accepting differences and reacting appropriately toward tricky situations are good points for managers as role models and leaders. Being aware of cultural differences in the team, listening and understanding the problems of team members and providing support and encouragement mean a lot.

Regardless of their cultural tendencies or in which cultural dimension they take place, appreciating the differences and taking the right steps for the acknowledgement of it by the team members is one of the solutions that is highly recommended by the managers in the sample. Education level and work experience may be the reasons behind this notion. First, it may be regarded that education is a must for personal developments of individuals. Individuals will be exposed to diverse ways of thinking and values through their education which is likely to influence the way they view and interpret the world around them. Hence, it is possible that they differently approach the problems when they are compared to people in the same culture. On the other hand, people confront certain problems in different settings during the business life. Working long years may be the indicative of getting some more experience and adopting new patterns to amend the mistakes made earlier (see Table 5).

Become approachable and eager to learn more: Almost 36 percent (five out of 14 ) of the participants highlight the importance of being approachable and eager to learn as to resolving the problems in multicultural teams. A manager must be accessible and assure that team members can talk about their problems whenever they need even after team meetings. It is important because some team members think that they should not bring some issues up in group meetings and they prefer privately talking about these issues or maybe even not talking at all. Being proactive is important at this point that letting members feel free to mention their concerns privately. Managers must be approachable, considerate, consultative and tolerant in this respect. Sense of humor is also an important skill for managers to have. It is vital to be able to build a relationship and better grasp the problems in the team.

This solution offer was made by managers classified in hierarchical cultures (see Table 5). It is likely that they frequently deal with the issues arising from their high propensity toward power distance and authority. Instead of keeping team members at arm's length or exerting control and authority over them, importance of being consultative, approachable or even paternalistic was emphasized by participants.

Communicate in a simple and straightforward way: Nearly 29 percent (four out of 14) of the participants state that communicating in a simple and straightforward way mostly hinders the debates and conflicts in the team. Managers need 
to be simple when it comes to communication. When it is simple and straightforward, it enables parties to build a sound relation and understanding. This is important because team members are likely to interpret the transmitted message in a wrong way if the message is not delivered straightforwardly. Therefore, communicating in a way that makes the expectations and problems clear and obvious is a milestone for an effective communication to avoid misapprehensions.

Compared to individualist cultures, it is avowable that collectivist cultures harbor high context in communication. In collectivist cultures the message is delivered in a subtle and indirect way and the way the message is transmitted is as significant as the words or, in some cases, more important than the words itself. The importance of establishing an open communication is stressed by managers coming from both collectivist and individualist cultures. The reason for this might be that collectivist managers face communication problems with 'low-context culture' team members or that individualist managers observe the source of conflicts related to communication in their teams and regard this as a problem that needs to be addressed. Either way, they are likely to think that the best way of handling this problem is straightforward communication (see Table 5).

Table 5: Solutions That Managers Come Up With and the Managers' CCDs

\begin{tabular}{|l|l|l|l|l|l|}
\hline & $\begin{array}{l}\text { Hierarchy/ } \\
\text { Equality }\end{array}$ & $\begin{array}{l}\text { Individualism/ } \\
\text { Collectivism }\end{array}$ & $\begin{array}{l}\text { Mastery/H } \\
\text { armony }\end{array}$ & $\begin{array}{l}\text { Monochronism/ } \\
\text { Polychronism }\end{array}$ & $\begin{array}{l}\text { Universalism/ } \\
\text { Particularism }\end{array}$ \\
\hline $\begin{array}{l}\text { Embrace diversity and } \\
\text { encourage group members to } \\
\text { acknowledge it }\end{array}$ & Both & Both & Both & Both & Both \\
\hline $\begin{array}{l}\text { Become approachable and } \\
\text { eager to learn more }\end{array}$ & Hierarchy & Collectivism & Harmony & Polychronism & Particularism \\
\hline $\begin{array}{l}\text { Communicate in a simple and } \\
\text { straightforward way }\end{array}$ & Both & Both & Both & Both & Both \\
\hline
\end{tabular}

\section{CONCLUSION}

Results of the study is expected to provide managers with a guideline about how to effectively manage multicultural teams and solve the conflicts arising within this context. Effective communication in multicultural teams is a big issue because misunderstandings may happen easily. Besides, working style and expectations slightly differ among the cultures. Managers must be aware of these differences to better understand, motivate team members and intervene when it is required. In addition, intolerance and lack of awareness of team members and managers about diversity is likely to lead to frictions and conflicts in the team. Therefore, team members are likely to underperform under these circumstances unless the manager knows how to handle them. It is because the manager is the only one who is in charge of setting the things right.

A work environment in which managers embrace diversity and encourage group members to acknowledge this diversity is quite significant. Multicultural teams are more prone to confront difficulties than homogenous teams. A manager must be approachable, considerate, consultative and tolerant and reassure that members can talk any problem whenever they need. Last but not least, in order to avoid any conflict and misunderstandings, a manager is expected to be simple and straightforward while communicating. There is no absolute accuracy when it comes to managing multicultural teams. However, when the manager embraces diversity and creates an environment that enables team members to appreciate each other's views while increasing the awareness of differences, the performance of team will be enhanced. A manager will be what his or her team is. If the team is a poor performer, the manager of the team will be viewed as a poor performer or vice versa. Successful managers are expected to possess the competency to adapt different management styles. They are also expected to be eager to learn more, and flexible enough to switch from one management style to another. This is significant to benefit multiple perspectives, different experiences, different problem-solving and decision-making styles and innovative ideas which prevail in multicultural teams.

This study, like any study, has some limitations. First of all, the study was conducted with a relatively small sample. Therefore, enlarging the size of the sample and reaching more participants will provide a more comprehensive understanding as to identifying the challenges and remedies in multicultural team management. In addition, it may be created scales to test the relationship between cultural dimensions and the challenges confronted in multicultural teams. Hence, in order to improve accuracy, surveys along with interviews may be used to complement the data. 


\section{REFERENCES}

Adler, N. J. (2002). International dimensions of organizational behavior, (4th Ed.). Cincinnati, OH: Southwestern.

Aritz, J., Walker, R. C. (2014). Leadership styles in multicultural groups: Americans and East Asians working together. International Journal of Business Communication, 51 (1), 72-92.

Behfar, K., Kern, M., Brett, J. (2006). Managing challenges in multicultural teams. In National culture and groups. Emerald Group Publishing Limited, 233-262.

Bettenhausen, K., Murnighan, J. K. (1985). The emergence of norms in competitive decision-making groups. Administrative Science Quarterly, 350-372.

Brett, J. M. (2007). Negotiating globally: how to negotiate deals, resolve disputes, and make decisions across cultural boundaries. John Wiley \& Sons, San Francisco: Jossey-Bass.

Browaeys, M. J., Price, R. (2008). Understanding cross-cultural management. Pearson education.

Chao, G. T., Moon, H. (2005). The cultural mosaic: a metatheory for understanding the complexity of culture. Journal of Applied Psychology, 90(6), 1128-1140.

De Dreu, C. K. W., Weingart, L. R. (2003). Task versus relationship conflict, team performance, and team member satisfaction: a metaanalysis. Journal of Applied Psychology, 88(4), 741-749.

Dunning, J. H. (2002). Global capitalism, FDI and competitiveness. Edward Elgar Publishing.

Ely, R. J. Thomas, D. A. (2001). Cultural diversity at work: the effects of diversity perspectives on work group processes and outcomes. Administrative Science Quarterly, 46(2), 229-273.

Halverson, C. B., Tirmizi, S. A. (Eds.). (2008). Effective multicultural teams: theory and practice. Springer Science \& Business Media.

Heimer, C., Vince, R. (1998). Sustainable learning and change in international teams: from imperceptible behavior to rigorous practice. Leadership \& Organization Development Journal, 19(2), 83-88.

Helvacıoğlu, N., Özutku, H. (2010). Kültürel farklılıkların yönetiminde insan kaynakları stratejilerinin rolü: IKEA örneği. Yönetim Bilimleri Dergisi, 8(1), 117-146.

Hofsteds, G. (1980). Culture's consequences. London: Sage.

Hofstede, G. (1991). Organizations and cultures: software of the mind. New York: McGrawHill.

Jarvenpaa, S. L., Leidner, D. E. (1999). Communication and trust in global virtual teams. Organizational Science, 10(6), $791-816$.

Jehn, K. A., Northcraft, G. B., Neale, M. A. (1999). Why differences make a difference: a field study of diversity, conflict and performance in workgroups. Administrative Science Quarterly, 44(4), 741-763.

Kirchmeyer, C., Cohen, A. 1992. Multicultural groups: their performance and reactions with constructive conflict. Group \& Organization Management, (17(2), 153-170.

Lisak, A., Erez, M. (2015). Leadership emergence in multicultural teams: the power of global characteristics. Journal of World Business, 50(1), 3-14.

Mäkilouko, M. (2004). Coping with multicultural projects: the leadership styles of Finnish project managers. International Journal of Project Management, 22(5), 387-396.

Markus, H. R., Kitayama, S. (1991). Culture and the self: implications for cognition, emotion, and motivation. Psychological Review, 98(2), 224-253.

Marquardt, M., Horvath, L. (2001). Global teams: how top multinationals span boundaries and cultures with high-speed teamwork. Palo Alto, CA: Davies-Black Publishing.

Marshall, M. N. (1996). Sampling for qualitative research. Family Practice, 13(6), 522-526.

Matveev, A., Milter, R. (2004). The value of intercultural competence for performance of multicultural teams. Team Performance Management, 10(5/6), 104-111.

Molinsky, A. (2013). Global dexterity: how to adapt your behavior across cultures without losing yourself in the process. Harvard Business Review Press.

Nardon, L., Steers, R. M. (2009). The culture theory jungle: divergence and convergence in models of national culture. Cambridge Handbook of Culture, Organizations, and Work, 3-22.

Oertig, M., Buergi, T. (2006). The challenges of managing cross-cultural virtual project teams. Team Performance Management: An International Journal, 12(1/2), 23-30. 
Palys, T. (2008). Purposive sampling. In L. M. Given (Ed.) the Sage Encyclopedia of Qualitative Research Methods, 2, 697-698. Los Angeles: Sage.

Ramthun, A. J., Matkin, G. S. (2012). Multicultural shared leadership: a conceptual model of shared leadership in culturally diverse teams. Journal of Leadership \& Organizational Studies, 19(3), 303-314.

Schneider, S. C., Barsoux, J. L. (2003). Managing across cultures. Pearson Education.

Sekaran, U., Bougie, R. (2017). Research methods for business: a skill building approach. John Wiley \& Sons.

Stahl, G. K., Maznevski, M., Voigt, A., Jonsen, K. (2010). Unraveling the effects of cultural diversity in teams: a meta-analysis of research on multicultural work groups. Journal of International Business Studies, 41, 690-709.

Thomas, D. C. (1999). Cultural diversity and work group effectiveness: an experimental study. Journal of Cross-Cultural Psychology, 30(2), $242-263$

Williams, K. Y., O'Reilly III, C. A. (1998). Demography and diversity in organizations: a review of 40 years of research. Research in Organizational Behavior, 20, 77-140. 